\title{
Effect of the Mediterranean diet in patients with chronic spontaneous urticaria
}

\author{
Havva Hilal Ayvaz * (1), Aliye Kuyumcu² (1)
}

\begin{abstract}
SUMMARY
OBJECTIVE: Patients with chronic spontaneous urticaria often want to be informed about dietary modifications. There have been many studies evaluating dietary approaches in chronic spontaneous urticaria. In this study, we aimed to investigate the relationship between adherence to the Mediterranean diet and chronic spontaneous urticaria.

METHODS: In this cross-sectional case-control observational study, 100 patients ( 70 males and 30 females, mean age: $38.6 \pm 13.0$ years) with chronic spontaneous urticaria and age- and sex-matched 100 healthy controls 70 males and 30 females, mean age: $38.7 \pm 13.8$ years) were enrolled. A validated 14-item questionnaire evaluating the Mediterranean diet score was used for the assessment of adherence to the Mediterranean diet. The severity and the control of chronic spontaneous urticaria were assessed by Urticaria Activity Score over 7 days and Urticaria Control Test, respectively.

RESULTS: The mean Mediterranean diet score in the patient group was $5.40 \pm 1.88$, whereas in healthy controls it was $6.30 \pm 1.39$ ( $p<0.001$ ). The Urticaria Activity Score over 7 days score of the patients was negatively correlated with the Mediterranean diet score, whereas the Urticaria Control Test score was positively correlated.

CONCLUSION: We reported that adherence to the Mediterranean diet may be an independent factor that decreases the risk of chronic spontaneous urticaria. It may also reduce the severity of chronic spontaneous urticaria symptoms.

KEYWORDS: Chronic Spontaneous Urticaria. Mediterranean Diet. Clinic activity.
\end{abstract}

\section{INTRODUCTION}

Chronic spontaneous urticaria (CSU) is a common skin disorder which is characterized by recurrent itchy wheals with or without angioedema ${ }^{1}$. In the majority of cases with CSU, the trigger cannot be identified and the patients try to suppress symptoms with many drugs including antihistamines or steroids for a long time. CSU has also a major impact on the quality of life of patients who have an insatiable desire for knowledge about their disease ${ }^{2}$. Thus, patients with CSU often ask clinicians about the required dietary modification.

The Mediterranean diet is a healthy eating pattern and is also found to be associated with reduced risk for cardiovascular diseases, stroke, metabolic syndrome, and carcinomas $s^{3-5}$. Furthermore, it was also reported that a decrease in the risk of chronic inflammatory diseases is associated with this diet $^{5}$.

There have been many studies about dietary approaches in CSU, including the diet without fish products, pseudoallergen-free diet, and low histamine $\operatorname{diet}^{6-8}$.

To the best of our knowledge, there has been no study about the relationship between CSU and Mediterranean diet adherence. The aim of this study was to evaluate the relationship between CSU and the Mediterranean diet score (MDS).

\footnotetext{
'Suleyman Demirel University, Faculty of Medicine, Department of Dermatology - Isparta, Turkey.

${ }^{2}$ Suleyman Demirel University, Faculty of Health Sciences, Department of Nutrition and Dietetics - Isparta, Turkey.

*Corresponding author: drhhilalayvaz@gmail.com

Conflicts of interest: the authors declare there are no conflicts of interest. Funding: none.

Received on January 31, 2021. Accepted on February 18, 2021.
} 


\section{METHODS}

This cross-sectional case-control observational study was reviewed by the Ethics Committee of Suleyman Demirel University Hospital and approved by the report of the decision number 212 on August 10, 2020. This study was conducted according to the Declaration of Helsinki and all subjects provided informed consent.

\section{Study population}

Patients diagnosed with CSU (having symptoms longer than 6 weeks and underlying triggering factors could not be defined), aged over 18 years and under 65 years, who presented to the dermatology outpatient clinic of Suleyman Demirel University Hospital between September 2020 and December 2020, and sexand age-matched healthy controls were considered for this study.

Participants with a history of cardiovascular or cerebrovascular events, active infection, and any uncontrolled systemic or skin diseases except CSU (for the patient group) and regular drug intake for any reason were excluded. Furthermore, CSU patients under the treatment of any systemic steroid such as omalizumab or immunosuppressive treatment such as cyclosporine were excluded.

\section{Outcome measurements}

Urticaria Activity Score over 7 days (UAS7) defines two symptoms: the quantity of wheals and intensity of itching, each on a $0-3$ scale every day. The UAS7 is the sum of the two daily ratings from seven consecutive days, yielding a total score of $0-42$, which means that UAS7 measures the severity of CSU symptoms in the previous week?

Urticaria Control Test (UCT) is a basic 4-item assessment tool to determine disease control in patients with CSU. It has mainly two parts, evaluating the frequency of symptoms and the suppression level of these symptoms by drugs. Low points indicate high disease activity and low disease control. The minimum and maximum UCT scores are 0 and 16, respectively. Less than 12 points indicate poorly controlled disease, whereas $\geq 12$ points indicate well-controlled disease ${ }^{10}$.

\section{Questionnaire of the Mediterranean diet score}

In the questionnaire of Mediterranean diet adherence, there are 14 questions based on assigning a score from 0 to 1 according to the daily intake of the eight components (Table 1) ${ }^{11}$.

Table 1. Validated 14-item questionnaire of Mediterranean diet adherence.

\section{Questions}

1. Do you use olive oil as main culinary fat?

2. How much olive oil do you consume in a given day (including oil used for frying, salads, out-of-house meals, etc.)?

3. How many vegetable servings do you consume per day? (1 serving: $200 \mathrm{~g}$ [consider side dishes as half a serving])

\begin{tabular}{|c|c|c|}
\hline 4. & How many fruit units (including natural fruit juices) do you consume per day? & $\geq 3$ \\
\hline 5. & $\begin{array}{l}\text { How many servings of red meat, hamburger, or meat products (ham, sausage, } \\
\text { etc.) do you consume per day? ( } 1 \text { serving: } 100-150 \mathrm{~g} \text { ) }\end{array}$ & $<1$ \\
\hline 6. & $\begin{array}{l}\text { How many servings of butter, margarine, or cream do you consume per day? (1 } \\
\text { serving: } 12 \mathrm{~g} \text { ) }\end{array}$ & $<1$ \\
\hline 7. & How many sweet or carbonated beverages do you drink per day? & $<1$ \\
\hline 8. & How much wine do you drink per week? & $\geq 7$ glasses \\
\hline 9. & How many servings of legumes do you consume per week? (1 serving: $150 \mathrm{~g}$ ) & $\geq 3$ \\
\hline 10. & $\begin{array}{l}\text { How many servings of fish or shellfish do you consume per week? ( } 1 \text { serving } \\
100-150 \mathrm{~g} \text { of fish or } 4-5 \text { units or } 200 \mathrm{~g} \text { of shellfish) }\end{array}$ & $\geq 3$ \\
\hline 11. & $\begin{array}{l}\text { How many times per week do you consume commercial sweets or pastries (not } \\
\text { homemade), such as cakes, cookies, biscuits, or custard? }\end{array}$ & $<3$ \\
\hline 12. & $\begin{array}{l}\text { How many servings of nuts (including peanuts) do you consume per week? (1 } \\
\text { serving } 30 \mathrm{~g} \text { ) }\end{array}$ & $\geq 3$ \\
\hline 13. & $\begin{array}{l}\text { Do you preferentially consume chicken, turkey, or rabbit meat instead of veal, } \\
\text { pork, hamburger, or sausage? }\end{array}$ & Yes \\
\hline 14. & $\begin{array}{l}\text { How many times per week do you consume vegetables, pasta, rice, or other } \\
\text { dishes seasoned with sofrito (sauce made with tomato and onion, leek, or } \\
\text { garlic and simmered with olive oil)? }\end{array}$ & $\geq 2$ \\
\hline
\end{tabular}

Criteria for 1 point

Yes

$\geq 4$ tbsp

$\geq 2$ ( $\geq 1$ portion raw or as a salad) 
The interviews were conducted by the same physician via a face-to-face method. Through this questionnaire, the consumption of vegetables, fruits, legumes, nuts, whole grains, fermented dairy products, fish and monounsaturated fats, average alcohol, and red meat of an individual was evaluated ${ }^{12}$. The minimum and maximum diet scores are 0 and 14 , and according to the Mediterranean diet the individuals with higher points were considered to be fed more consistently ${ }^{12}$.

\section{Statistical analysis}

Data were analyzed using SPSS version 18.0 (SPSS Inc., Chicago, IL, USA). Continuous variables were reported as mean $\pm S D$, and categorical variables were reported as percentages and counts. The Student's $t$-test was used for comparisons of normally distributed variables, and the Mann-Whitney U test was used for non-normally distributed variables if two groups existed. One-way analysis of variance was used to compare normally distributed variables among three groups. Tukey's test was used for post-hoc analysis. Categorical variables were compared using the $\chi^{2}$ test or Fisher's exact test, as appropriate. Pearson's correlation coefficients were used to assess the strength of relationships between continuous variables, and Spearman's correlation analysis was performed for noncontinuous and categorical variables. Univariate and multivariate logistic regression analysis consisted of the MDS and the variables (depression, high-density lipoprotein [HDL], low-density lipoprotein [LDL], creatinine, and fibromyalgia). In all the analyses, the $\mathrm{p}<0.05$ was considered to be statistically significant. The number of patients required for this study in each group was 100 patients for sampling with $90 \%$ power and 0.05 type I error as at least 97 (R 3.0.1. open source program). The primary effect variable was determined as one point of MDS.

\section{RESULTS}

A total of 100 patients (30 males and 70 females) with CSU and sex- and age-matched healthy controls (30 males and 70 females) were enrolled in this study. Descriptive features of the participants are given in Table 2. The mean age in the patient group was $38.6 \pm 13.0$ years (with an age range 18-65) and in the control group it was $38.7 \pm 13.8$ years $(\mathrm{p}=0.983)$. Furthermore, there were no significant differences between the two groups concerning BMI, waist circumference, smoking, and use of alcohol (Table 2). Since depression and/or fibromyalgia syndrome was higher in the patient group, there were significant differences between the groups ( $\mathrm{p}<0.018$ and $\mathrm{p}=0.030$, respectively). The mean levels of laboratory parameters of the participants were shown in Table 1.
Table 2. Baseline characteristics and laboratory parameters of the study groups.

\begin{tabular}{|c|c|c|c|}
\hline & $\begin{array}{l}\text { Patient } \\
\text { group } \\
(n=100)\end{array}$ & $\begin{array}{l}\text { Control } \\
\text { group } \\
(n=100)\end{array}$ & p-value \\
\hline Age, years & $38.6 \pm 13.0$ & $38.7 \pm 13.8$ & 0.983 \\
\hline Female, n (\%) & $70(70)$ & $69(69)$ & 0.878 \\
\hline $\mathrm{BMI}, \mathrm{kg} / \mathrm{m}^{2}$ & $24.8 \pm 3.82$ & $24.2 \pm 4.0$ & 0.306 \\
\hline $\begin{array}{l}\text { Waist } \\
\text { circumference }\end{array}$ & $83 \pm 3.8$ & $85 \pm 2.6$ & 0.357 \\
\hline $\begin{array}{l}\text { Mediterranean } \\
\text { diet score }\end{array}$ & $5.40 \pm 1.88$ & $6.30 \pm 1.39$ & $<0.001$ \\
\hline Smoking, n (\%) & $34(34)$ & $43(43)$ & 0.191 \\
\hline $\begin{array}{l}\text { Use of alcohol, n } \\
\text { (\%) }\end{array}$ & $12(12)$ & $12(12)$ & 1.000 \\
\hline \multicolumn{4}{|l|}{ Comorbidities } \\
\hline Depression, n (\%) & $15(15)$ & $5(5)$ & 0.018 \\
\hline $\begin{array}{l}\text { Asthma, allergies, } \\
\text { rhinitis, } n(\%)\end{array}$ & $6(6)$ & $2(2)$ & 0.149 \\
\hline $\begin{array}{l}\text { Diabetes } \\
\text { mellitus, n (\%) }\end{array}$ & $5(5)$ & $8(8)$ & 0.390 \\
\hline $\begin{array}{l}\text { Hypothyroidism, } \\
\mathrm{n}(\%)\end{array}$ & $14(14)$ & $7(7)$ & 0.106 \\
\hline $\begin{array}{l}\text { Rheumatologic } \\
\text { disease, } \mathrm{n}(\%)\end{array}$ & $5(5)$ & $1(1)$ & 0.097 \\
\hline $\begin{array}{l}\text { Fibromyalgia, } \\
\mathrm{n}(\%)\end{array}$ & $14(14)$ & $5(5)$ & 0.030 \\
\hline $\begin{array}{l}\text { Hypertension, } \\
\text { n (\%) }\end{array}$ & $6(6)$ & $5(5)$ & 0.756 \\
\hline \multicolumn{4}{|l|}{$\begin{array}{l}\text { Laboratory } \\
\text { parameters }\end{array}$} \\
\hline Glucose, mg/dL & $97.4 \pm 12.3$ & $98.8 \pm 15.6$ & 0.945 \\
\hline $\begin{array}{l}\text { Creatinine, mg/ } \\
\mathrm{dL}\end{array}$ & $0.76 \pm 0.10$ & $0.73 \pm 0.14$ & 0.049 \\
\hline $\begin{array}{l}\text { Total cholesterol, } \\
\mathrm{mg} / \mathrm{dL}\end{array}$ & $196.0 \pm 27.0$ & $196.1 \pm 25.3$ & 0.975 \\
\hline $\mathrm{LDL}-\mathrm{C}, \mathrm{mg} / \mathrm{dL}$ & $137.6 \pm 29.2$ & $125.6 \pm 27.5$ & 0.003 \\
\hline $\mathrm{HDL}-\mathrm{C}, \mathrm{mg} / \mathrm{dL}$ & $42.52 \pm 9.46$ & $48.15 \pm 9.23$ & 0.002 \\
\hline $\begin{array}{l}\text { Triglyceride, } \\
\text { mg/dL }\end{array}$ & $142.1 \pm 38.5$ & $146.1 \pm 52.8$ & 0.536 \\
\hline
\end{tabular}

Data are given as mean $\pm \mathrm{SD}, \mathrm{n}$ (\%) or median (interquartile range or lower-upper limit). BMI: body mass index; HDL-C: high-density lipoprotein cholesterol; LDL-C: low-density lipoprotein cholesterol. * $\mathrm{p}$-value is significant at the 0.05 level. 
Concerning LDL and HDL levels, there were significant differences between the two groups ( $p=0.003$ and $p=0.002)$ and the patient group had higher levels of LDL and HDL.

The mean UCT score of the patients with CSU was 8.66 \pm 3.60 , the mean UAS7 score was $23.73 \pm 11.34$, and the mean MDS was $5.40 \pm 1.88$. The MDS of healthy controls was $6.30 \pm 1.39$, which was significantly different from the patient group $(\mathrm{p}<0.001)$.

In particular, the UAS7 score was negatively correlated with the MDS, whereas the UCT score was positively correlated with the MDS (Figure 1).
Furthermore, univariate and multivariate logistic regression analyses were conducted to identify variables that are predictive of CSU in these 100 patients (Table 3). The variables included MDS, the presence of depression and fibromyalgia syndrome, creatinine, and LDL and HDL cholesterol levels. In univariate analysis, all parameters except creatinine levels were found to be significantly associated with CSU. Moreover, in multivariate analysis, the MDS, HDL levels, and depression were found to be significantly associated with CSU.
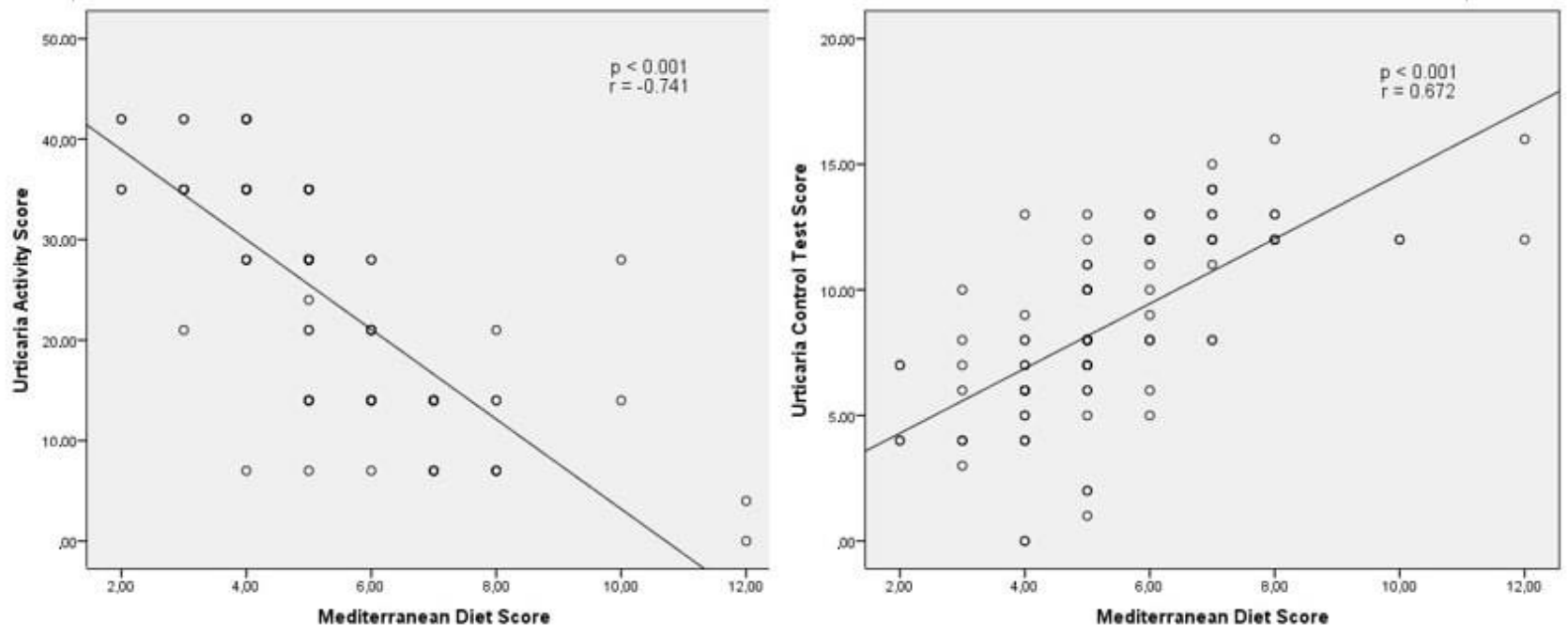

Figure 1. Correlation schemes of Mediterranean diet score with both Urticaria Activity Score over 7 days and Urticaria Control Test.

Table 3. Multivariate logistic regression analysis to predict CSU.

\begin{tabular}{|c|c|c|c|c|}
\hline & $\begin{array}{l}\text { Univariable } \\
\text { OR }(95 \% \mathrm{Cl})\end{array}$ & p-value & $\begin{array}{l}\text { Multivariable } \\
\text { OR }(95 \% \mathrm{Cl})\end{array}$ & $\mathrm{p}$-value \\
\hline Mediterranean diet score & 1.409 (1.167-1.701) & $<0.001$ & $1.433(1.173-1.752)$ & $<0.001$ \\
\hline Depression & $0.298(0.104-0.855)$ & 0.024 & $0.320(0.280-0.361)$ & 0.047 \\
\hline Fibromyalgia & $0.323(0.112-0.935)$ & 0.037 & $0.341(0.140-0.563)$ & 0.81 \\
\hline Creatinine & $0.098(0.009-1.007)$ & 0.051 & & \\
\hline LDL-C & $0.985(0.975-0.995)$ & 0.004 & 0.997 (0.984-1.009) & 0.163 \\
\hline HDL-C & 1.070 (1.034-1.107) & $<0.001$ & 1.049 (1.002-1.098) & 0.043 \\
\hline
\end{tabular}

CSU: chronic spontaneous urticarial; Cl: confidence interval; OR: odds ratio; HDL-C: high-density lipoprotein cholesterol; LDL-C: low-density lipoprotein

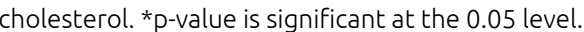




\section{DISCUSSION}

The relationship between CSU symptoms and diets has been investigated several times and the results are controversial. Some studies using diet restrictions showed that diet restrictions are unnecessary and ineffective ${ }^{13,14}$, whereas other studies suggest that diet restrictions may result in complete or significant remission of symptoms in patients with CSU ${ }^{15-17}$. It was argued that these results may be related to the psychological relief of the patients after food restrictions and the importance of the oral challenge in $\mathrm{CSU}^{13,14}$. Although there was no particular restriction of diet exactly, our results showed that adherence to the Mediterranean Diet was negatively correlated with the severity of the symptoms of the patients with CSU.

In a study by Son et al. ${ }^{18}$. the effect of a histamine-free diet was evaluated in 22 patients with CSU, and a significant decrease in the severity of the disease and also in the plasma histamine level was found to be associated with this diet. Furthermore, Wagner ${ }^{16}$ and Guida ${ }^{19}$ reported similar results that a histamine-free diet may reduce the severity of symptoms in CSU. In fact, the recommendations of a histamine-free diet and the Mediterranean diet are almost the opposite. In a histamine-free diet, histamine-rich foods, such as some fishes, chicken, spinach, pork, mayonnaise, yogurt, cheese, ketchup, wine, beer, cabbage or radish, soybean paste, red pepper, are restricted, whereas in the Mediterranean diet consumption of red wine, seafood, all vegetables, and fruits are suggested ${ }^{18}$.

Besides, many studies evaluate the effects of a pseudoallergen-free diet on disease activity in $\mathrm{CSU}^{15,17}$. According to the results of these studies, a pseudoallergen-free diet is effective and beneficial for patients with CSU. A wide number of nutrients may act as pseudoallergens such as natural compounds (including all fruits, vegetables except mushrooms, tomatoes, and olives), all preservatives including foods (dyes, preservatives, and flavorings), vasoactive compounds (acetylsalicylic acid, histamine, and nitric oxide), and fats except butter and plant oils ${ }^{5,17}$. In fact, regarding the similarity of the pseudoallergen-free diet and the Mediterranean diet, both of them suggest preservative-free foods, butter, and plant oils. In the Mediterranean diet fruits are prominent, whereas they are restricted in the pseudoallergen-free diet.

Adherence to the Mediterranean diet has not been evaluated in patients with CSU in the literature until 2021. It was reported that the risk of cardiovascular diseases, stroke, chronic inflammatory diseases, and even carcinomas can be reduced with the Mediterranean $\operatorname{diet}^{3-5}$. In addition, it was shown that the anti-inflammatory and antioxidant effects of the Mediterranean diet have the potential to reduce systemic inflammation and oxidative stress which play a role in the pathophysiology of CSU disease $^{1,20}$. In this preliminary study, we reported that adherence to the Mediterranean diet may be an independent factor that may lower the occurrence of CSU. It may also reduce the severity of CSU symptoms in patients. These results may be obtained due to the following features of the Mediterranean diet: in this diet, it is frequent that the distance between the source of food and the consumer is short, and local food is more preferred in the Mediterranean countries than the global food ${ }^{21}$. Local food is often fresh and involves no preservatives or less amount of the artificial ingredients. Similarly, there are often less pesticide residues in the local food and the Mediterranean in-house cooking methods are usually nutrient-preserving, allowing the preservation of the phytochemicals ${ }^{22}$.

In addition, our study results are similar to those of many studies in which the prevalence of depression and fibromyalgia is higher in patients with CSU than healthy controls ${ }^{23,24}$. Adherence to the Mediterranean diet can reduce the frequency of these diseases; however, further controlled trials are required to support this observation.

This study has some limitations. We assessed only dietary habits and adherence to the Mediterranean diet of the participants, but not the physical activity or the psychological stress in their life. Therefore, the results and correlations of this study should be verified by future studies with broader and more detailed methods.

\section{CONCLUSIONS}

Although this diet seems to work in Turkish CSU patients, the relationship between compliance with the Mediterranean diet and disease severity may not be significant in CSU patients in other countries due to genetic changes or nutritional habits. One should perform further randomized controlled trials with larger samples in order to confirm this observation regarding the relationship between the Mediterranean diet and CSU disease. However, it is advised that the adoption of a healthy lifestyle and diet should be combined with the holistic management of patients with CSU.

\section{AUTHORS' CONTRIBUTIONS}

AHH: Conceptualization, Data Curation, Formal Analysis, Software, Writing - Original Draft. KA: Conceptualization, Data Curation, Formal Analysis, Software, Writing - Review $\&$ Editing. 


\section{REFERENCES}

1. Kocatürk E, Grattan C. Is chronic urticaria more than skin deep? Clin Transl Allergy. 2019;9:48. https://doi.org/10.1186/ s13601-019-0287-2

2. Ograczyk-Piotrowska A, Gerlicz-Kowalczuk Z, Pietrzak A, Zalewska-Janowska AM. Stress, itch and quality of life in chronic urticaria females. Postepy Dermatol Alergol. 2018;35(2):15660. https://doi.org/10.5114/ada.2018.75237

3. Kuyumcu A, Kuyumcu MS, Ozbay MB, Ertem AG, Samur G. Nesfatin-1: a novel regulatory peptide associated with acute myocardial infarction and Mediterranean diet. Peptides. 2019;114:10-6. https://doi.org/10.1016/j.peptides.2019.04.003

4. Tektonidis TG, Åkesson A, Gigante B, Wolk A, Larsson SC. A Mediterranean diet and risk of myocardial infarction, heart failure and stroke: a population-based cohort study. Atherosclerosis. 2015;243(1):93-8. https://doi.org/10.1016/j. atherosclerosis.2015.08.039

5. Di Daniele N, Noce A, Vidiri MF, Moriconi E, Marrone G, Annicchiarico-Petruzzelli $M$, et al. Impact of Mediterranean diet on metabolic syndrome, cancer and longevity. Oncotarget. 2017;8(5):8947-79. https://doi.org/10.18632/oncotarget.13553

6. Jaros J, Shi VY, Katta R. Diet and Chronic Urticaria: Dietary Modification as a Treatment Strategy. Dermatol Pract Concept. 2019;10(1):e2020004. https://doi.org/10.5826/dpc.1001a04

7. Daschner A, Fernández-Fígares V, Valls A, Frutos C, Rodero $M$, Ubeira FM, et al. Different fish-eating habits and cytokine production in chronic urticaria with and without sensitization against the fish-parasite Anisakis simplex. Allergol Int. 2013;62(2):191-201. https://doi.org/10.2332/ allergolint.12-OA-0504

8. Siebenhaar F, Melde A, Magerl M, Zuberbier T, Church MK, Maurer M. Histamine intolerance in patients with chronic spontaneous urticaria. J Eur Acad Dermatol Venereol. 2016;30(10):1774-7. https://doi.org/10.1111/jdv. 13778

9. Patruno C, Napolitano M, Ferrucci S, Brambilla L, Hansel K, Corazza $M$, et al. Four-week urticaria activity score-7 as a useful patient-reported outcome to assess chronic spontaneous urticaria: a multicentre study evaluation of adherence and patients' perspective. Acta Derm Venereol. 2019;99(10):903-4. https://doi.org/10.2340/00015555-3231

10. Weller K, Groffik A, Church MK, Hawro T, Krause K, Metz M, et al. Development and validation of the Urticaria Control Test: a patient-reported outcome instrument for assessing urticaria control. J Allergy Clin Immunol. 2014;133(5):1365-72,1372. e1-6. https://doi.org/10.1016/j.jaci.2013.12.1076

11. Martínez-González MA, García-Arellano A, Toledo E, Salas-Salvadó J, Buil-Cosiales P, Corella D, et al. A 14-item Mediterranean diet assessment tool and obesity indexes among high-risk subjects: the PREDIMED trial. PLoS One. 2012;7(8):e43134. https://doi.org/10.1371/journal. pone.0043134

12. Bach A, Serra-Majem L, Carrasco JL, Roman B, Ngo J, Bertomeu I, et al. The use of indexes evaluating the adherence to the
Mediterranean diet in epidemiological studies: a review. Public Health Nutr. 2006;9(1A):132-46. https://doi.org/10.1079/ phn2005936

13. Hsu ML, Li LF. Prevalence of food avoidance and food allergy in Chinese patients with chronic urticaria. $\mathrm{Br} J$ Dermatol. 2012;166(4):747-52. https://doi.org/10.1111/j.13652133.2011.10733.x

14. Sánchez J, Sánchez A, Cardona R. Dietary habits in patients with chronic spontaneous urticaria: evaluation of food as trigger of symptoms exacerbation. Dermatol Res Pract. 2018;2018:6703052. https://doi.org/10.1155/2018/6703052

15. Magerl M, Pisarevskaja D, Scheufele R, Zuberbier T, Maurer M. Effects of a pseudoallergen-free diet on chronic spontaneous urticaria: a prospective trial. Allergy. 2010;65(1):78-83. https:// doi.org/10.1111/j.1398-9995.2009.02130.x

16. Wagner N, Dirk D, Peveling-Oberhag A, Reese I, Rady-Pizarro U, Mitzel H, Staubach P. A Popular myth - low-histamine diet improves chronic spontaneous urticaria - fact or fiction? J Eur Acad Dermatol Venereol. 2017;31(4):650-5. https://doi. org/10.1111/jdv.13966

17. Zuberbier T, Chantraine-Hess S, Hartmann K, Czarnetzki BM. Pseudoallergen-free diet in the treatment of chronic urticaria. A prospective study. Acta Derm Venereol. 1995;75(6):484-7. https://doi.org/10.2340/0001555575484487

18. Son JH, Chung BY, Kim HO, Park CW. A histamine-free diet is helpful for treatment of adult patients with chronic spontaneous urticaria. Ann Dermatol. 2018;30(2):164-72. https://doi.org/10.5021/ad.2018.30.2.164

19. Guida B, Martino CD, Martino SD, Tritto G, Patella V, Trio R, et al. Histamine plasma levels and elimination diet in chronic idiopathic urticaria. Eur J Clin Nutr. 2000;54(2):155-8. https:// doi.org/10.1038/sj.ejcn.1600911

20. Billingsley $\mathrm{HE}, \mathrm{Carbone} \mathrm{S}$. The antioxidant potential of the Mediterranean diet in patients at high cardiovascular risk: an in-depth review of the PREDIMED. Nutr Diabetes. 2018;8(1):13. https://doi.org/10.1038/s41387-018-0025-1

21. Caradonna F, Consiglio O, Luparello C, Gentile C. Science and healthy meals in the world: nutritional epigenomics and nutrigenetics of the Mediterranean diet. Nutrients. 2020;12(6):1748. https://doi.org/10.3390/nu12061748

22. Palermo M, Pellegrini N, Fogliano $V$. The effect of cooking on the phytochemical content of vegetables. J Sci Food Agric. 2014;94(6):1057-70. https://doi.org/10.1002/jsfa.6478

23. Yener M, Erturan I, Ceyhan AM, Inal EE, Kazanoglu OO. The evaluation of prevalence of fibromyalgia in patients with chronic urticaria. Med Sci Monit. 2013;19:757-61. https:// doi.org/10.12659/msm.889626

24. Tzur Bitan D, Berzin D, Cohen A. The association of chronic spontaneous urticaria (CSU) with anxiety and depression: a nationwide cohort study. Arch Dermatol Res. 2021;313(1):33-9. https://doi.org/10.1007/s00403-020-02064-3 